\title{
CONCEPTUAL MODELLING OF UPSTREAM OFFSHORE SEAWEED SUPPLY
}

\author{
PER ENGELSETH $^{1}$ \& NINA PEREIRA KVADSHEIM ${ }^{2}$ \\ ${ }^{1}$ Department of Logistics, Molde University College, Norway \\ ${ }^{2}$ Department of Logistics, Møreforskning, Molde, Norway
}

\begin{abstract}
A new form of offshore aquaculture is currently under development in Norway. This article argues for an ecosystem-based development of this future supply chain rooted in experiences in petroleum logistics, aquaculture and cold chains. A conceptual model provides basis for further research to facilitate designing this form of supply chain as a sustainable system.

Keywords: aquaculture, cold chains, ecosystems, petroleum logistics, seaweed, supply chain management, traceability.
\end{abstract}

\section{INTRODUCTION}

In addition to considering the biological aquaculture phase of production, seaweed aquaculture needs also to consider what characterises this form of environmentally contingent networked supply operations. While seaweed production currently takes place close to the shore, given new technologies, it is more advantageous to localize this production far out at sea. Such production may involve different forms of equipment. One commonly proposed technology is to mount a rope between buoys at sea, and let the seaweed grow on these ropes. Large parks of such ropes may be described as vineyards at sea. This implies 'offshore' production. Seaweed can be supplied for many different uses. These various market needs, including intermediary supply chain viewpoints, must be specified and need to be coupled with how to satisfy these various needs through operations.

Aquaculture is a fast-growing food-producing industry that presently supplies almost $50 \%$ of the world's fish food, and according to Lovatelli et al. [1], such an industry has undoubtedly the greatest potential to meet the growing demand for aquatic food. It is estimated that at least an additional 40 million tonnes of marine food will be required by 2030 to maintain the current per capita consumption, given the estimated growth in global population over the next couple of decades [1]. Worldwide environmental concerns about industrial pollution and depletion of natural resources have led to the cultivation of more renewable resources such as seaweed biomass. In 2012, an unprecedented 20.8 million tonnes (wet weight) was produced, a large amount compared to the 6.4 million tonnes produced in 2000 [2]. Seaweeds provide opportunities for production at sea, a product that has multiple uses and is a promising resource to contribute to the Europe's societal challenges of food security and climate change in the future. Moreover, there is greater competition for land space arising from the growing demand for food, energy and accommodation due to the high population density in Europe [3]. Hence, seaweed cultivation far out at sea could be a solution to reduce the pressure on land and its resources. Nevertheless, such an offshore location of production implies challenges at the operational as well as management levels. These challenges need to be explored and analysed. This includes considering the sustainable logistics of upstream seaweed production including harvesting, and how this logistics may secure quality supply. This also includes considering features of handling seaweed, a fresh and therefore vulnerable material. The new offshore growing location for seaweed production implies also new operational, management and 
environmental challenges. This includes the technical equipment needed to harvest, transport, handle and store seaweed in its new offshore part of the supply chain. These upstream operations are carried out in what commonly is denoted as a 'supply chain'. This chain may be considered a network, and alternatively be analysed as a complex system: an ecosystem.

To develop a conceptually based understanding of what characterizes this forthcoming seaweed supply chain to be different from other related industries and associated literature is crucial. These considerations from earlier research in supply chains include (1) petroleum logistics, since this form of operation is associated with supporting offshore production; (2) aquaculture, since this industry is also associated with growing biological matter in controlled forms in the sea as well as transporting these foods to shore locations; and (3) cold chains, since these supply chains handle perishable and vulnerable items that demand traceability. These three empirically founded aspects are considered in this article and then associated with ecosystems thinking. The reason to take an ecosystems approach to supply chain management $(\mathrm{SCM})$ is because of the fundamental reflection that this industry is inherently deeply embedded in nature.

The predominant aim of this article is to conceptually model the upstream portion of the seaweed supply chain based on the ecosystems approach that includes materials flow, resources used to transform the seaweed materials, types of agents and how these varied agents interact in this supply chain and to finally point out the environmental factors of concern. We have relied on secondary data coupled with own experiences with the seaweed industry through previous informal encounters over a number of years. This includes taking part in the PROMAC (Energy efficient PROcessing of MACroalgae in blue-green value chains) project [4], which is directly associated with our research issue. It is still considered a case study since we apply different data sources on a real-life problem and may be viewed as the foundation for data collection in accordance with an overall case study research strategy [5]. The conceptual model is developed in line with complex systems methodology, and represents the initial phase in conceptual modelling paving a way for computer-based simulation following e.g. agent-based modelling [6-8]. First, we describe in brief the ongoing PROMAC [4] project also associated with the development of seaweed production in Norway. This should provide the basis for designing this form of supply chain.

\section{THE PROMAC PROJECT}

This study builds on the knowledge for sustainable processing and applications of seaweed as human food and animal feed, developed by an interdisciplinary project, PROMAC. The project owner is Møreforskning AS [9] located in the cities of Ålesund and Molde in coastal Western Norway. The main aim of this project is to provide a knowledge base for energyefficient and sustainable processing of macroalgae (seaweed) as human food as well as animal feed applications, thus contributing to the development of value chains based on natural resources and improved energy utilization. In PROMAC, seaweed constitutes a renewable and non-traditional naturally occuring raw material that can be screened for its nutritionally beneficial components to be processed and refined into novel products. Systematic research into the effective handling and processing of a new marine resource will contribute to technological innovations concerning future uses of seaweeds in both blue and green sector food production. Besides, PROMAC [1] addresses the energy requirements of seaweed processing technology in novel ways, i.e. by investigating the potential for utilizing excess energy from industrial activity in coastal areas, which often constitutes an unexploited resource. Sustainable resource utilization has high priority in PROMAC [1], and both human food and animal feed applications from macroalgae are expected products. Investigations of the nutritional 
value and health effects (for and on humans and domestic animals) will address food safety, in addition to helping select seaweed products with the highest commercial potential as applications in the production cycle. As marine macroalgae are about to become the basis for a new bio-economy in Norway, PROMAC [1] will test emerging value chains for all major elements of sustainability. PROMAC [1] will evaluate benefits and costs of macroalgal products along such value chains (from raw material to market and consumer) through product-based Life Cycle Assessments (LCA) and business model evaluations.

\section{PETROLEUM LOGISTICS}

'Petroleum logistics' represents an industry-specific type of logistics. Its conceptualization is empirically driven. Logistics is generically understood as the technical aspect of SCM [10, 11]. Simply speaking, logistics is associated with resource transformation through end-to-end flows of goods supported by an information flow and money. In accordance with Parsons [12], such transformation may be denoted as 'production'. This is importantly associated with an aim to achieve customer value. Following Alderson's marketing channels model [13], production aims ultimately to create value associated with time, place and form features of the delivered product, measured ultimately in the hands of the end-user. The key logistics activities are transport, storage and materials handling. Note that fabrication is not considered as a logistical operation. Transport is associated with supply purpose in changing the location of resource objects. Storage is value associated with holing the resource items over time. For instance, fabricating summer apparel in the winter, and then storing these items until the winter season hits the market. Materials handling binds together the logistics and fabrication activities, namely, transport, storage and fabrication. Accordingly, logistics implies a management challenge associated with securing customer-responsive supply. This is an inter-organizational challenge. SCM seeks to facilitate the total production including important logistics operations, from a complete supply network perspective. In line with Håkansson and Persson [14], the network metaphor denotes that each agent in this industrial network manages a set of mainly long-term business relationships, and the relationships are individually associated with different supply chains. Christopher [15] rightly states that the supply chain actually is a network.

Petroleum logistics is developed in Norway mainly to handle the type of petroleum industry found there. The extraction of petroleum resources in Norway always takes place at offshore subsea or platform facilities. This similarity with producing and harvesting seaweed as an offshore aquaculture facility is the reason to consider whether research in this industrial sector may provide valuable findings for developing production. It is therefore mainly the logistics in supporting the offshore petroleum production that we address here, and not the extraction of petroleum or its raw material fabrication. Supplies to offshore petroleum facilities is described by Engelseth and Pettersen [16] as a logistics flow that is configured as a loop. This is illustrated in Fig. 1:

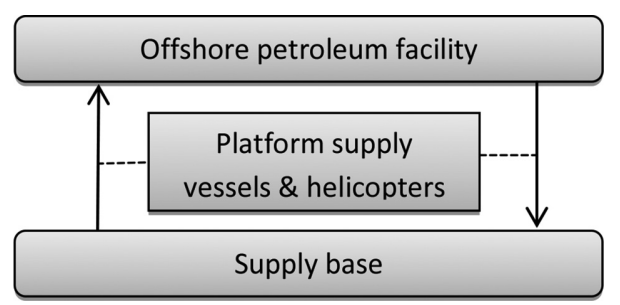

Figure 1: Petroleum logistics as a looped flow [16]. 
Subsea facilities are automated, and therefore only intermittently serviced by the platform supply vessels (PSV). Helicopters transport personnel and sometimes smaller goods that are urgently needed. The figure also indicates a reverse logistics flow of waste and equipment. This reverse logistics flow is essential not only because it transports wastes that are hazardous and must therefore undergo treatment on land [17] but also to transport personnel returning from the platform by helicopter. The supply base is a specialized industrial park with harbour facilities. The platform houses a number of workers and therefore needs to be regularly serviced. There are three main operations at these facilities: (1) fabrication of petroleum raw material, (2) maintenance and modification (MMO), and (3) drilling to ensure production volume through securing sufficiently high pressure in the wells. This production location is, as Engelseth and Pettersen [16] point out, associated with a range of uncertainties implying that it is beneficial to consider petroleum logistics as a complex system. These uncertainties are associated with the following factors viewed, as shown in the figure on the following page, in combination:

- Limited capacity at the platform, meaning operations usually must be sequenced after each other,

- Timing of drilling or MMO project start-up and termination,

- Plan-related irregularities in drilling and MMOs,

- Competing service suppliers meaning competency may change,

- Logistics operations involving numerous different complementary agents that differ from shipment to shipment,

- Changing weather conditions affecting both PSV transport and personnel transport by helicopter.

These factors put together lead to logistics processes that have a clearly emergent character. Currently, these logistics operations are managed through a planning paradigm. A master plan is used to plan operations at the platform. In addition, a plan is created using an Excel spreadsheet. This plan indicates what is loaded onto a specific shipment by a PSV. However, there is an element of uncertainty related to this plan that is used to manage the supply risk associated with PSV transport. The planners network with the different agents associated with the transport, that is (1) the oil company responsible for the platform, (2) the supply base operating materials handling at the port, (3) the PSV shipping operator, (4) transport companies delivering goods to the supply base for onward transport by the PSV, and (5) sub-suppliers of drilling, MMO and other types of goods destined for the platform. In the reverse logistics flow, waste management companies are in addition associated with this network. In relation to seaweed production, the petroleum logistics provides insights regarding operations far out at sea. The main contribution is considering this form of production, which is highly embedded in nature, as a naturally complex system. When modelling this system, it is essential to consider the highly emergent character of production. Seaweed is an aquaculture product, planted bio-matter in the sea. This means that it is more a contingent of a natural ecosystem than offshore petroleum production that handles non-living product substances.

\section{SEAFOOD AQUACULTURE}

In Norway, salmon and trout are by far the most commonly produced species. This production takes place through a chain of activities at different locations, bound together by transport as described, based on research by Engelseth [18], in Fig. 2:

This production chain endures in total over approximately 3 years. One of the major salmon producers in Norway, with a $25 \%$ market share, organizes its upstream salmon 


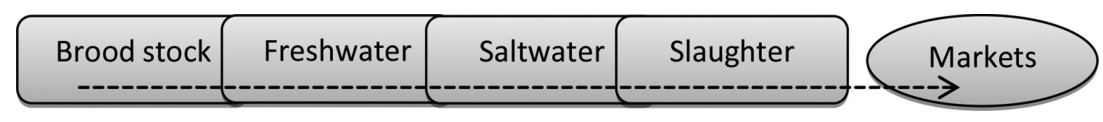

Figure 2: The seafood aquaculture production chain.

production prior to export as a vertically integrated supply chain [18]. The brood stock production takes place at a small number of specialized facilities that produce the fish roe. The roe is sent by mail in specialized packaging to the freshwater facilities that hatch and grow the fish over a period of 16 months. Then the fish is transported mainly by tank trucks to the seawater facilities that are located relatively close to the shore in the fjords of Norway. Technology is now being developed and tried out involving larger offshore aquaculture facilities. Here, the fish grow over a period of 15-20 months. Finally, the fish are transported by wellboats to the slaughterhouse. The well-boat is a specialized transport resource that permits the transport of living biological material. The slaughter as well as the packaging process for transport to customers takes only a day in the case of fresh fish. In the case of frozen goods, the products may be stored for a prolonged time period. The distribution of fresh fish is associated with market preferences. In addition, the seafood production represents a raw material for a vast array of different consumer goods. Offshore seaweed production may be considered as a form of aquaculture. However, instead of animate material, the seaweed is a plant. This means that offshore seaweed production is a hybrid between current seafood aquaculture production and land-based agriculture. This also indicates that production technologies, including logistics, may be applied in offshore seaweed production. However, in addition to considering the aquaculture phase of growing the fish, seaweed aquaculture needs to also consider what characterizes this form of environmentally contingent networked supply operations. There are several locations with varying technologies involved. The rapid expansion of the seaweed aquaculture industry will result in the demand for more resources (e.g. freshwater, feed) and space to accommodate it. Hence, expanding production of seaweed farther off the coast and offshore where more space is available and where competition is currently less intense, may minimize environmental impacts from and on seaweed aquaculture as well as optimize food safety [8].

\section{COLD CHAINS}

Cold chains indicate a type of supply chains that are temperature regulated. This type of temperature-controlled production is found in a range of industries. Typically, many types of food supply take place in such supply chains. The seaweed is, in its initial state, fresh goods. As many forms of produced bio-matter, they are processed at a later stage of production. 'Cold' indicates a temperature requirement of the environment of the produced goods associated with logistics. In food chains, goods are processed to manipulate durability. Cooling is one such form of processing. In cases of fresh supply, temperature is regulated to adap to the specific product requirements; different foods require different fresh storage temperatures. The minimum level recommended when freezing goods is $18^{\circ} \mathrm{C}$. Industrial freezing is often considerably lower. Cooled transport of fresh foods usually prolongs the life of these foods to a number of days or weeks, depending on the product. In the case of freezing, the life-span is widened to a number of months. Clearly, the cold chain technically enhances the economy of the supply chain. The main effort is associated with maintaining the temperature. In a supply chain, materials handling poses a major challenge since it sometimes takes place at room temperature between the types of operations involved: transport, storage or fabrication. 
Furthermore, the equipment used in cold chains always runs a risk of breaking down. Such breakdowns may even take place unnoticed if the refrigeration systems simply fluctuate in temperature during the logistics activity. Customers therefore require assurance that the cold chain has been in effect in its entirety. Cold chain logistics is therefore closely interlinked with traceability [19]. The traceability of goods is associated with control of the goods flow and being able to inform about this flow after it has taken place. Traceability is accordingly associated predominately with the information flow. It uses goods registrations, processes this type of information to create documentation of product transformation in the supply chain including the temperature log. One of the key aspects of traceability in food chains is that it demands retrieval of past information from different supply chain agents. This is also a form of physical distribution, meaning it is inherently sequentially interdependent [20], goods information if it passes on from one agent to another as they produce, accumulated in volume. However, usually goods control information is stored by the individual actors. If this is the case, traceability is ensured by facilitating the retrieval of product history information from the different supply chain agents involved in its logistics activities. This information is located in different non-integrated databases. SCM, associated with integrating the various agents and resources involved in production to better coordinate their different production legs of responsibility, is accordingly a key facilitator of achieving quality traceability [21]. Furthermore, traceability is associated with customer needs, although this is a very intermittent need. It is a form of latent competence that is triggered upon enquiry [22]. This enquiry usually comes from a downstream agent who needs this information to decide whether to purchase, or from a customer who wants to communicate a quality discrepancy associated with the purchased goods. The creation of information enabling tracing goods is a continuous operation. In addition, how this is organized is dependent on some form of long-term planning since it involves collaboration between different supply chain agents organized in a multi-tier supply chain. Traceability is therefore a unique competence that is demanded in contemporary food chains, and especially in cold chains, since these are more vulnerable to discrepancies founded on technical errors. Likewise, in seafood chains, there will be a need to develop advanced systems for monitoring and registering information about its production. The use will be to secure traceability as a stepping stone to ensure production and product quality. From an ecosystems perspective, traceability provides assurance that production is ecologically sustainable to the company managers, the market and the wider society. This enhances the ethical standing of production as well as the economic soundness of production in a marketplace increasingly sensitive to the sustainability of production in a global ecosystem.

\section{SEAWEED PRODUCTION AS AN ECOSYSTEM}

This article provides examples of preceding research that has been argued as beneficial when attempting to model a seaweed production from the perspective of an SCM being a complex system. These strands of literature are however based on a mainly technical and economical perspective of organizational development. As discussed at the end of each of these three lines of contribution, they may easily and fruitfully be associated with ecosystems thinking. The motivation to base this research on ecosystems thinking was described in a preliminary observation that the seaweed industry, in its immature state as an industry with enormous growth potential, is naturally located embedded in nature. The experiences from seafood aquaculture denote that it is not possible to block out nature from such production. On the mass scale, this industry is medicating its production through use of antibiotics, etc. Still 
problems are paramount such as the fleeing of aquaculture fish, contamination of the seafloor etc. In its infancy, seaweed production may still navigate by taking away a fundamental step of designing this production at the proposed offshore locations in a sustainable manner.

Ecology was termed by Haeckel in 1866 as the science of relationship between organism and the surrounding outer world [23]. 'Ecosystems' indicate considering ecology from a system's perspective. 'Systems thinking' implies research sensitivity to the connectedness, relationships, patterns and context of phenomena. Parts are not viewed in isolation and the whole is never equal to the sum of the parts in a system. Complexity implies variation in systems thinking where processes within the system are given emergent properties; following Broad, the features of the system at a higher level of complexity will not be found at a lower level of complexity [24]. Nature may easily be described as inherently systemic. As Capra and Luisi [25] state, based on recent studies in many fields of natural sciences, that '... nature does not show us any isolated building blocks, but rather appears as a complex web of relationships between the various parts of a unified whole'. This designates a line of research where systems thinking is not isolated to being an artificially induced scientific approach. Systemic properties are found in nature regardless of the glasses the researcher wears. Ecosystems may accordingly be considered as 'out there' even though we do not have the words to describe them. This is a powerful understanding that we regard as important in developing an SCM. It should not be limited to organizational, economic and technological considerations. Also, describing ecology as a 'fourth pillar' complementing the existent considerations may be intrinsically wrong if one considers an ecosystem as the nature of life in its totality. Nature not only envelopes production, it is a part of it. Developing SCM along these, for now rudimentary considerations, as an ecosystem, faces a range of challenges. Therefore, in this study we choose to remain simple in our modelling effort and leave many questions and considerations unwrapped. We propose here a simple conceptual model of how we expect a seaweed supply to look like in the future indicating factors that future research must take into consideration. This is accordingly our simple model of the seaweed supply chain illustrated in Fig 3:

From an ecosystems perspective, this model depicts different considerations. Each of these may be elaborated further on. The text box in Fig. 3 'organization, technology and economy' indicates variation in technical solutions. There are many ways by which production, harvesting, transport and processing may be done. Also, an organization encompasses the supply chain picture, suggesting that there is more than a single agent involved in this effort. Herein lies the potential for both conflict and harnessing network complementarities. The text box 'sustainability and traceability' indicates the ethical quality of production and informing

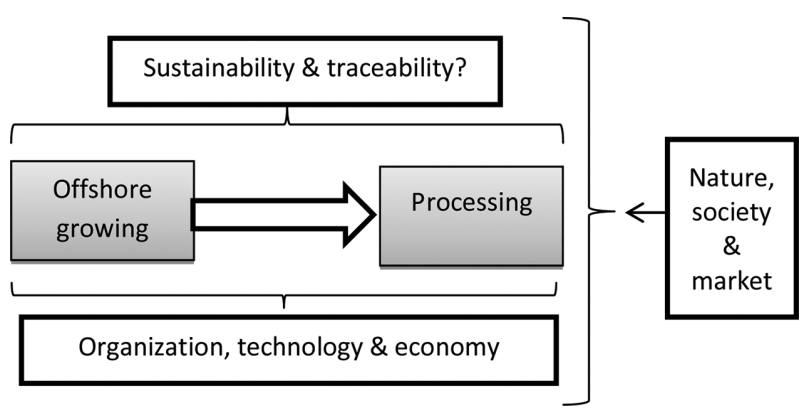

Figure 3: The seaweed supply chain. 
about this quality. Clearly, this quality is dependent on organizational, technology and economic considerations. The text box 'nature, society and market' points towards the rest of the model. This box actually contains three different subsystems that are to be modelled separately. This pointing indicates a direction of impact, that these are contextual factors that the supply chain design is dependent on. Before it is possible to create a computer-based model to simulate this production more empirical data needs to be collected on the following issues all treated as ecosystem subsystems nested in a complete supply chain ecosystem:

- Nature, society and market considerations

- Growing the seaweed as an aquaculture

- Harvesting and transporting the seaweed to land

- Processing, where and how.

Each of these subsystems when individually modelled as flexible systems facilitating variation in design, are integrated into a whole. Based on empirical findings features of the different subsystems may be described. This research agenda provides the foundation for computer modelling to simulate these subsystems first individually, and then interlink these different subsystems.

\section{CONCLUDING REMARKS}

This study reveals that there is by far more than one way to design a future offshore seaweed supply chain. It is recommended that such design be scientific, meaning not be a coincidental, and potentially environmentally hazardous, development process outcome. Taking into account the features of nature as an ecosystem, exploiting the resources offshore should strive to design a balanced systemic and harmonious form of offshore seaweed production. We argue this is possible if the network of actors make this project a supply chain of its own, a form of service chain characterized by how people and other resources are pooled and mutually adjust to collaborate as an ecosystem itself.

\section{REFERENCES}

[1] Lovatelli, A., Aguilar-Manjarrez, J. \& Soto, D., Expanding mariculture farther offshore: Technical, environmental, spatial and governance challenges. FAO Technical Workshop, Orbetello, Italy, 2010.

[2] FAO, Yearbook of Fishery and Aquaculture Statistics. In FAO (Ed.), Dataset Global Aquaculture Production 1950-2012, 2012, available at http://www.fao.org/fishery/statistics/ global-aquaculture-production/query/en

[3] Taelman, S.E., Champenois, J., Edwards, M.D., De Meester, S. \& Dewulf, J., Comparative environmental life cycle assessment of two seaweed cultivation systems in North West Europe with a focus on quantifying sea surface occupation. Algal Research, 11, pp. 173-183, 2015. https://doi.org/10.1016/j.algal.2015.06.018

[4] PROMAC project website, available at http://promac.no/ Downloaded 19.11.2016.

[5] Thomas, G., How to Do Your Case Study, London, Sage Publications, 2015.

[6] Gilbert, N., Agent-Based Models, London: Sage, 2007.

[7] Checkland, P.B., Systems thinking, systems practice, Chichester, UK: John Wiley \& Sons, 1981. 
[8] Checkland, P.B., Soft systems methodology in action, John Wiley \& Sons, Chichester, UK: 2001.

[9] Møreforskning, available at http://www.moreforsk.no/ Downloaded 19.11.2016.

[10] Glossary of terms, available at www.cscmp.org. The "logistics management" definition of the influential Council of Supply Chain Management Professionals describes how SCM as principles of integration and collaboration supports logistics as technical operations. Downloaded 19.11.2016.

[11] Lambert, D.M., Cooper, M.C. \& Pagh, J.D., Supply chain management: implementation issues and research opportunities. The International Journal of Logistics Management, 9(2), pp. 1-19, 1998.

https://doi.org/10.1108/09574099810805807

[12] Parsons. T., Structure and processes in modern societies, The Free Press of Glencoe, New York, 1960.

[13] Alderson, W., Dynamic marketing behavior: a functionalist theory of marketing, Richard D. Irwin, Homewood, IL, 1965.

[14] Håkansson, H. \& Persson, G., Supply chain management: the logic of supply chains and networks. International Journal of Logistics Management, 15(4), pp. 11-26, 2004. https://doi.org/10.1108/09574090410700202

[15] Christopher, M., Logistics and supply chain management, 5th Edn., London, UK: Financial Times. 2016.

[16] Engelseth, P. \& Pettersen, T.M., Agent-based modelling of offshore upstream petroleum logistics. International Journal of Design \& Nature and Ecodynamics, 11(4), pp. 635-643, 2016.

https://doi.org/10.2495/DNE-V11-N4-635-643

[17] Engelseth, P., Developing the service value: a case study of waste management in offshore petroleum logistics. WIT Transactions on Ecology and the Environment, 202, pp. 135-146, 2016.

https://doi.org/10.2495/wm160131

[18] Engelseth, P., Aligning end-to-end seafood supply through a series of markets. International Journal of Production Economics, 173, pp. 99-110, 2016.

https://doi.org/10.1016/j.ijpe.2015.12.012

[19] Parenreng, S.M., Pujawan, N., Karningsih, P.D. \& Engelseth, P., Mitigating risk in tuna supply through traceability system development. International Food and Agribusiness Management Review, 19(1), pp. 1-24, 2016.

[20] Thompson, J.D., Organizations in action, New York, NY: McGraw Hill, 1967.

[21] Engelseth, P., Wongthatsanekorn, W. \& Charoensiriwath, C., Food product traceability and customer value. Global Business Review, 15(4 suppl), pp. 87S-105S, 2014.

[22] Engelseth, P., Food product traceability and supply network integration. Journal of Business and Industrial Marketing, 24(5/6), pp. 421-430, 2009. https://doi.org/10.1108/08858620910966291

[23] Haeckel, E., Generelle Morphologie der Organismen, Berlin: Reimer, 1866.

[24] Broad, C.D., The mind and its place in nature, Routledge and Kegan Paul, London, 1925.

[25] Capra, F. \& Luisi, P.L., The systems view of life: a unifying vision, Cambridge University Press, Cambridge UK, 2014. 